\title{
Assess the Prevalence of Low-Birth-Weight Babies and Its Risk Factors among Postnatal Mothers in Wardha District
}

\author{
Yugandhara Dilip Hingankar1, Bali Thool², Vaishali Taksande³ \\ 1, 2,3 Department of Obstetrics and Gynaecological Nursing, Smt. Radhikabai Meghe Memorial College of \\ Nursing, Datta Meghe Institute of Medical Sciences, Sawangi (M), Wardha, Maharashtra, India.
}

\section{ABSTRACT}

\section{BACKGROUND}

Babies of low birth weight (LBW) include 2,499 g or less weight as stated by WHO. LBW consists of VLBW which is below $1500 \mathrm{~g}$ and extremely low birth weight which is lesser than $1000 \mathrm{~g}$. The normal gross weight of the infant at the time of delivery is $2500-4200 \mathrm{~g}$. The cause of LBW is preterm birth or a slow prenatal growth rate. The survival rate is determined by the baby's birth weight. Several risk factors are also associated such as multiple pregnancies, poor nutrition, hypertension, drug addiction or intake of alcohol. It is very necessary to prevent LBW rather than treating it after birth. The present study was done to assess the prevalence of lowbirth-weight babies and its risk factors among postnatal mothers in the Wardha district.

\section{METHODS}

A descriptive research design was undertaken, and 35 postnatal mothers in the Wardha district were selected for the study, the data was collected with the help of a structured questionnaire and a risk factor assessment scale was used for postnatal mothers.

\section{RESULTS}

The result of the study shows the prevalence rate of LBW babies among postnatal mothers as $49.18 \%$, and there was an assessment of risk factors among postnatal mothers from selected areas and association of prevalence of low birth with selected demographic variables. There was no association of prevalence of lowbirth-weight babies among postnatal mothers in relation to demographic variables.

\section{CONCLUSIONS}

This study concludes that there is a good prevalence of LBW babies but mothers didn't have adequate knowledge regarding LBW of babies and risk factors that affect the mother as well as the foetus.

\section{KEY WORDS}

Low Birth Weight, Preterm, Gestation, Dehydration, Hyperthermia, Hypothermia
Corresponding Author: Dr. Yugandhara Dilip Hingankar,

Dept of Obstetrics and Gynaecological Nursing, Smt. Radhikabai Meghe Memorial College of Nursing, Datta Meghe Institute of Medical Sciences, Sawangi (M),

Wardha, Maharashtra, India.

E-mail: yuga.hingankar1996@gmail.com

DOI: $10.14260 /$ jemds/2021/631

How to Cite This Article:

Hingankar YD, Thool B, Taksande V. Assess the prevalence of low-birth-weight babies and its risk factors among postnatal mothers in Wardha district. J Evolution Med Dent Sci 2021;10(36):3094-3098, DOI: $10.14260 /$ jemds $/ 2021 / 631$

Submission 21-10-2020,

Peer Review 24-07-2021,

Acceptance 03-08-2021,

Published 06-09-2021.

Copyright (C) 2021 Yugandhara Dilip Hingankar et al. This is an open access article distributed under Creative Commons Attribution License [Attribution 4.0 International (CC BY 4.0)] 


\section{BACKGROUND}

The babies born with an estimated birth weight of $2500 \mathrm{gm}$ and less are said to be LBW infants. Most of the low-birthweight babies are healthy but some of them might have serious problems. ${ }^{1}$ Infants born before 37 weeks mean before the time of gestation that will lead to poor development and poor weight gain, which are the main reasons and causes of low birth weight because they remain for very little time in the womb. ${ }^{2}$ Most of the babies gain weight in the last few weeks of pregnancy. Intrauterine growth restriction is also the main cause of low birth weight and the main reason for it is problems with the placenta, mother's health and baby's health. ${ }^{3}$ Some of the other reasons are; previous history related to low birth babies, age less than 17 or more than 35 years of age. ${ }^{4}$ Babies weighing less than 1,500 grams at birth are considered as very low birth weight (VLBW). Babies who weigh less than 1,000 grams are extremely low birth weight. More than $95 \%$ of infants of low-birth-weight babies are born in developing countries. ${ }^{5}$ The incidence rate of lowbirth-weight babies in developing countries is $16.5 \%$ which tends to be double that of developed countries. In India 30 $35 \%$ of babies are LBW and more than half of these infants are full-term babies. The main reason for babies born with LBW is either they were born early or they were born on time but didn't grow enough during pregnancy, which led to IUGR which is one of the specific causes. ${ }^{6}$ It also includes prematurity, preeclampsia and other problems related to pregnancy such as poor pregnancy nutrition, multiple births, infection in mom and baby before birth and rubella. Mothers with poor socio-economic conditions have very low birth weight babies, in areas where low birth weight income is directly related to the poor nutritional health of the mother at the time of pregnancy. Increase in the prevalence rate of specific and non-specific infections, or from pregnancy related complications which is associated with poor financial background and poor economic conditions and more physical work during pregnancy ultimately lead to poor foetal growth. ${ }^{7}$ The present study had been taken up to assess the prevalence of low-birth-weight babies and its risk factors among postnatal mothers in the Wardha district.

\section{METHODS}

A quantitative approach and descriptive research designs were used for 35 postnatal mothers in the Wardha district, data were collected from postnatal mothers, the number of underweight infants was gathered from the register which was maintained during delivery and followed according to normal vaginal delivery and caesarean section births. The study was conducted from June 2020 to August 2020.The data collection procedure required 1 week per plan. $3-4$ normal vaginal deliveries took place in a day, accordingly data had been collected. The researcher introduced herself to the staff and explained the study requirements to take permission for the study from the selected areas of Wardha district.

The tool was validated by an expert from obstetrics and gynaecological nursing, the investigator developed the tool after updating his/her theoretical knowledge regarding low birth weight and guidance from the expert along with the review of literature that helped in developing the tool necessary for the study. A structured questionnaire was developed and a risk assessment scale was used to determine risk factors among postnatal mothers. (Aruna K. The prevalence of low birth weight and its risk factors among postnatal mothers in the selected hospitals in Madurai). English expert had revised the tools and later it was translated in to Marathi language without changing its meaning. And the tools were correct and appropriate for postnatal mothers.

Then interviews were taken with the following questionnaires and a risk assessment scale was prepared according to the risk factors. Written informed consent was obtained in cases where the researchers had to help with clarification of questions or filling out questionnaires. The structured questionnaire consisted of various parts including demographic variables and the questions related to knowledge regarding risk factors for low-birth-weight babies. It consisted of four sections such as obstetrical factors, antenatal factors, nutritional factors, foetal factors. Each section carried a different score which is stated below in detail. Yes / No type pattern of questions were prepared by the investigator based on the risk factors of low birth weight. Each question carried a maximum score of 1 and a minimum score of 0 .

The Datta Meghe Institute of Medical Sciences Ethics Committee (DU); the report was accepted by the Institutional Ethics Committee.

\section{Statistical Analysis}

All findings were summarized by concentrations and percentages, categorically. The program used in the study was SPSS 24.0 and the edition of GraphPad Prism 7.0, and P < 0.05 was regarded as a degree of significance.

Statistical analysis of the assessment of the prevalence of low-birth-weight babies and its risk factors among postnatal mothers in the Wardha district was carried out to find the significant difference between those values. Analysis of the data was done by using descriptive and inferential statistics.

Descriptive statistics were used to describe the basic features of the data in the study. They provided simple summaries about the sample and the measures. Together with simple graphics analysis, they formed the basis of virtually every quantitative analysis of data.

\section{RESULTS}

Analysis and interpretation of the data collected from 35 samples of postnatal mothers in the Wardha district. Analysis and interpretation were based on the objectives of the study and a structured questionnaire to collect the prevalence score was used for data collection.

This section deals with the percentage wise distribution of postnatal mothers with regard to their demographic characteristics.

The data obtained to describe the sample characteristics included age, education, occupation, gravida and type of diet respectively. 


\begin{tabular}{|c|c|c|c|}
\hline & $\begin{array}{l}\text { Demographic } \\
\text { Variables }\end{array}$ & $\begin{array}{c}\text { No of Postnatal } \\
\text { Mothers }\end{array}$ & Percentage \\
\hline \multirow{4}{*}{ Age (years) } & $18-22$ yrs. & 14 & 40.0 \\
\hline & $23-28$ yrs. & 13 & 37.1 \\
\hline & $29-34$ yrs. & 6 & 17.1 \\
\hline & $35-40$ yrs. & 2 & 5.7 \\
\hline \multirow{4}{*}{ Education } & Primary & 5 & 14.3 \\
\hline & Secondary & 11 & 31.4 \\
\hline & Higher Secondary & 12 & 34.3 \\
\hline & Graduate & 7 & 20.0 \\
\hline \multirow{4}{*}{ Occupation } & Government Sector & 3 & 8.6 \\
\hline & Private Sector & 5 & 14.3 \\
\hline & Homemaker & 13 & 37.1 \\
\hline & Unemployed & 14 & 40.0 \\
\hline \multirow{2}{*}{ Gravida } & Primigravida & 21 & 60.0 \\
\hline & Multigravida & 14 & 40.0 \\
\hline \multirow{3}{*}{ Type of diet } & Vegetarian & 17 & 48.6 \\
\hline & Non-Vegetarian & 6 & 17.1 \\
\hline & Mixed & 12 & 34.3 \\
\hline \multicolumn{4}{|c|}{$\begin{array}{c}\text { Table 1. Distribution of Demographic Variables among Post-Natal } \\
\text { Mothers }\end{array}$} \\
\hline
\end{tabular}

The above table shows that $40 \%$ of the postnatal mothers were in the age group of $18-22$ years, $37.10 \%$ were in the age group of $23-28$ years, $17.10 \%$ were in the age group of $29-34$ years and $5.70 \%$ of postnatal mothers were in the age group of 35 - 40 years, $14.30 \%$ of the postnatal mothers were educated up to primary standard, $31.40 \%$ up to secondary, $34.30 \%$ of them were educated up to higher secondary and $20 \%$ of them were graduates, $8.60 \%$ of the postnatal mothers were doing government job, $14.30 \%$ of them were doing private service, $37.10 \%$ of them were housewives and $40 \%$ of the postnatal mothers were unemployed, $60 \%$ of the postnatal mothers were primigravida's and $40 \%$ of them were multi-gravidas, $60 \%$ of the postnatal mothers were vegetarians, $17.10 \%$ of them were non-vegetarians and $34.30 \%$ of them were consuming mixed diet.

Assessment of Level of Prevalence of LowBirth-Weight Babies among Postnatal Mothers in Selected Hospitals

Assessment of level of prevalence of low-birth-weight babies show that $2.86 \%$ of the postnatal mothers had poor level of prevalence of low birth babies, $57.14 \%$ had good and $40 \%$ of the postnatal mothers had a very good level of prevalence of low-birth-weight babies. The minimum prevalence score was 14 and the maximum prevalence score was 17 . The mean prevalence score was $6.88 \pm 1.62$ and the mean percentage of prevalence score was $49.18 \pm 11.59$. The prevalence of lowbirth-weight babies among postnatal mothers was $49.18 \%$.

Assessment of Risk Factors of LBW Babies among Postnatal Mothers in Selected Hospital

\begin{tabular}{|c|c|c|c|c|c|}
\hline & Risk Factors & Present & $\%$ & Absent & $\%$ \\
\hline \multirow{3}{*}{$\begin{array}{l}\text { Obstetrical } \\
\text { Factors }\end{array}$} & I had severe morning sickness & 20 & 57.14 & 15 & 42.86 \\
\hline & $\begin{array}{l}\text { I experience unpleasant symptoms } \\
\text { headache }\end{array}$ & 13 & 37.14 & 22 & 62.86 \\
\hline & $\begin{array}{l}\text { During pregnancy routine, I was } \\
\text { said about the health condition }\end{array}$ & 21 & 60.00 & 14 & 40.00 \\
\hline \multirow{2}{*}{$\begin{array}{l}\text { Antenatal } \\
\text { Factors }\end{array}$} & I feel good after my sleep & 18 & 51.43 & 17 & 48.57 \\
\hline & I took adequate rest & 14 & 40.00 & 21 & 60.00 \\
\hline \multirow{3}{*}{$\begin{array}{l}\text { Nutritional } \\
\text { Factors }\end{array}$} & I am conscious of my weight & 19 & 54.29 & 16 & 45.71 \\
\hline & I tried to eat well-balanced meals. & 21 & 60.00 & 14 & 40.00 \\
\hline & I reduced eating salt & 19 & 54.29 & 16 & 45.71 \\
\hline \multirow{4}{*}{$\begin{array}{l}\text { Foetal } \\
\text { Factors }\end{array}$} & $\begin{array}{l}\text { I had done all the screenings to } \\
\text { check foetal growth }\end{array}$ & 16 & 45.71 & 19 & 54.29 \\
\hline & I had done all blood investigations & 14 & 40.00 & 21 & 60.00 \\
\hline & $\begin{array}{l}\text { I had attended regular follow-ups } \\
\text { and my routine check-ups }\end{array}$ & 14 & 40.00 & 21 & 60.00 \\
\hline & I had taken medicines properly & 17 & 48.57 & 18 & 51.43 \\
\hline
\end{tabular}

Graph no.1 shows assessment with obstetrical factors; $57.14 \%$ of the postnatal mothers had severe morning sickness, $37.14 \%$ experienced unpleasant symptoms like headache and $60 \%$ of the postnatal mothers had informed about health condition during pregnancy routine, $51.43 \%$ felt good after sleep and $40 \%$ of postnatal mothers took an adequate risk.

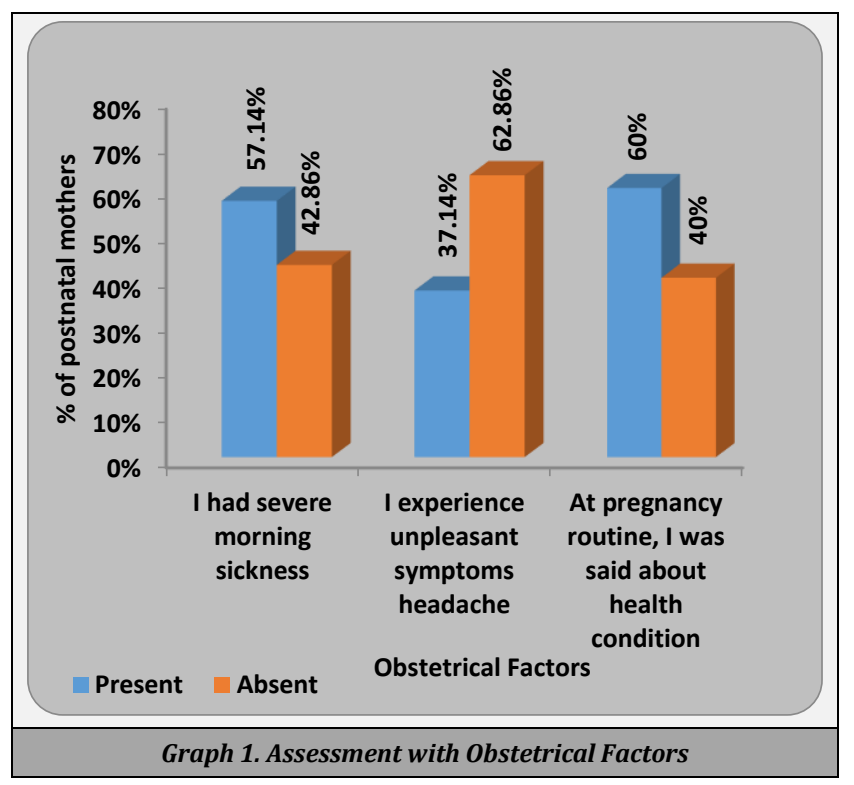

Graph no. 2 shows the assessment with nutritional factors; $54.29 \%$ of the postnatal mothers were conscious about their weight, $60 \%$ tried to eat well-balanced meals and $54.29 \%$ of postnatal mothers reduced eating salt.

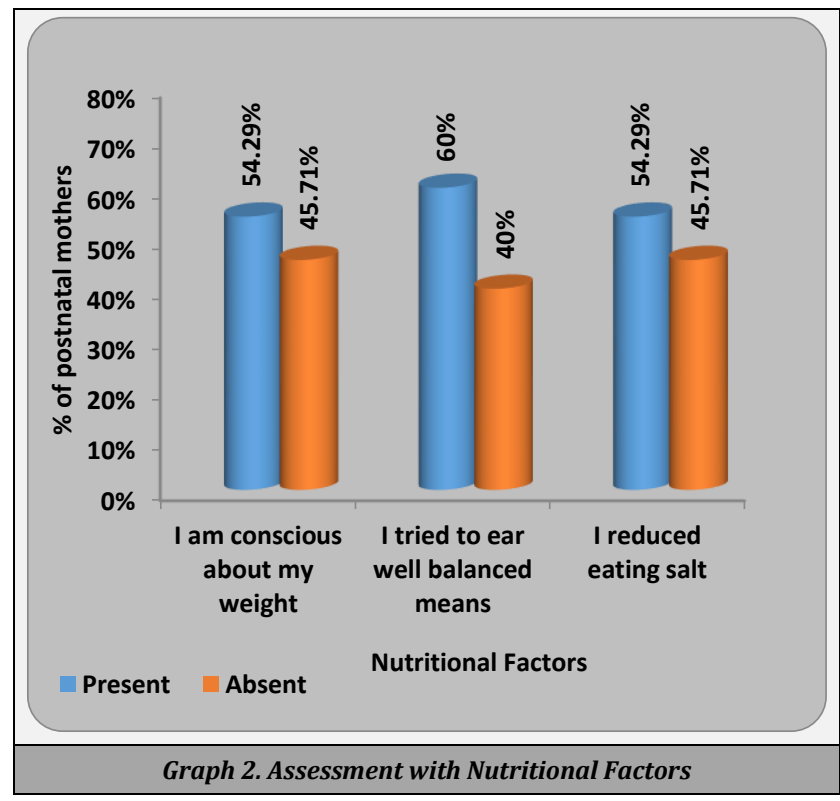

Graph no. 3 shows the assessment with foetal factors; $54.29 \%$ of the postnatal mothers attended all the screenings to check foetal growth, $40 \%$ of them had got all the blood investigations done, $40 \%$ of them attended regular follow ups and routine check-ups and $48.57 \%$ of postnatal mothers had taken medicines properly. 


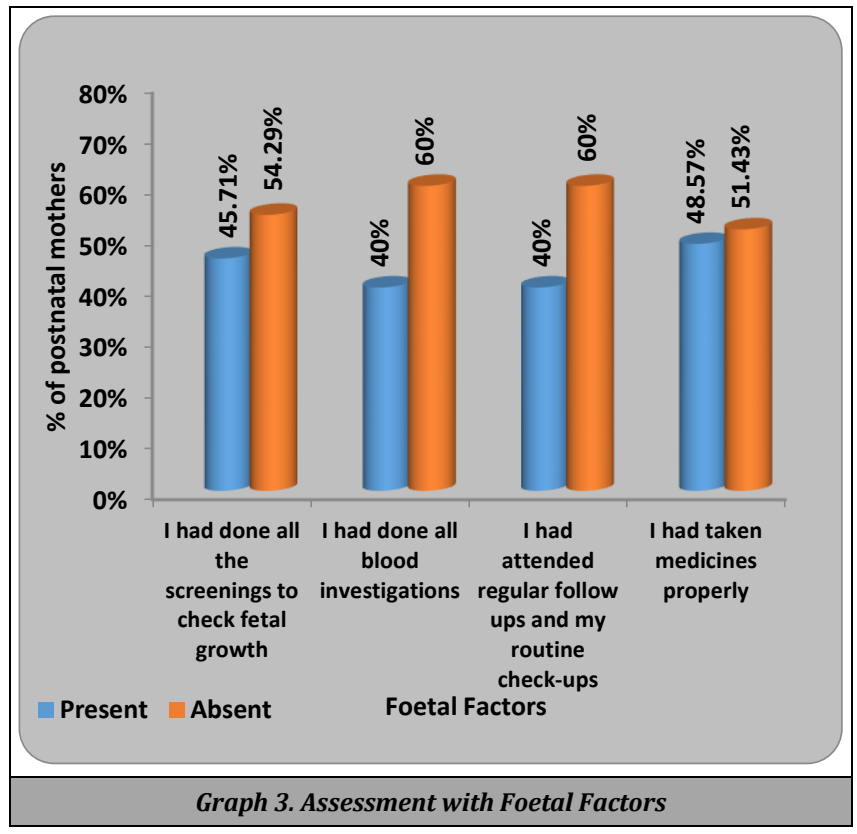

DISCUSSION

The national and international health organizations had recommended that all babies must be weighed soon after birth. ${ }^{8}$ The WHO had defined LBW to the birth weight less than 2500 gms, it is more common in developing countries than in developed countries and a birth weight below $2500 \mathrm{~g}$ results in poor health outcomes. Highly specialized staff and advanced technologies are required in improving health care facilities, essential care during childbirth and immediate care during the initial postpartum period and very few critical interventions may lead to recovery. Many conditions are responsible for perinatal death that can be prevented or treated. In the era of advanced medical facilities, it is moreover based on medicine and criteria of diagnosis and management of illness, changes more frequently. ${ }^{9}$

A similar study was conducted in the Government Rajaji hospital in Madurai District. A quantitative research approach, an explorative research design was used and the research ended with the conclusion that more importance should be given for good antenatal care to prevent low birth weight. Teaching-learning methods should be used with question and answers with effective audio-visual aids such as booklet and video as an effective and useful method to improve knowledge of mothers related to prevention of lowbirth-weight babies. ${ }^{10}$

Another similar research study was conducted in a tertiary hospital in Nanded, Maharashtra, to assess the maternal risk factors associated with LBW neonates, and they found a significant association between gestational age, type of delivery and sex of babies, haemoglobin level and weight gain. But there was no significant association between the cast, maternal age, socioeconomic status. And it ends with the conclusion that the factors which found a significant association were the independent risk factors for LBW.11

A research study was conducted in Bharatpur, Nepal to find out the prevalence of LBW and the association of socioculture and maternal risk factors among the institutional deliveries. The study results showed that there was a high incidence of LBW babies in institutional deliveries, dietary intake during pregnancy and period of gestation was significantly associated with LBW. By providing adequate knowledge and effective antenatal care services with proper home care during pregnancy and proper education to family members and mothers will reduce the risk. ${ }^{12}$

More increase in low-birth-weight babies is accounted by the higher number of babies with intrauterine growth retardation rather than preterm birth of babies. The UNICEF and WHO have recommended that all infants must be weighed at the time of birth, and it should be recorded at birth for new-born health record for later use in monitoring the infant's growth. ${ }^{13}$ At the population basis the birth weight data is collected every 5 or every 10 years since the incidence of population changes slowly. In every institution, maternity hospital and health care centres, birthweight is recorded and maintained. ${ }^{14}$ The institutional deliveries are rare and the LBW rate may be high because of the high incidence of preterm deliveries and other complications. Causes of preterm births are divided into four factors and they are maternal factor, foetal factor, medical factor and iatrogenic factors. ${ }^{15}$ The maternal factor includes incompetence of cervix, antepartum haemorrhage, or placenta previa, previous premature delivery, and some medical conditions which affect mothers during pregnancy. Foetal factor includes multiple pregnancies and congenital anomalies, medical factors include the condition where the mother had to be induced before full term on medical grounds, for example, gestational diabetes in mothers during pregnancy, major cardiac illness, foetal distress and hypoxia. Iatrogenic factors include improper diagnosis of maturity in elective pregnancy being one of the causes. The birth rate and death rates should be recorded. ${ }^{16}$

\section{CONCLUSIONS}

This research led to the following finding after the thorough analysis and it led to the conclusion that the prevalence rate of low-birth-weight babies among postnatal mothers was $49.18 \%$, and there was an assessment of risk factors among postnatal mothers from selected hospitals and association of prevalence of low birth with selected demographic variables. There was no association of prevalence of low-birth-weight babies among postnatal mothers about demographic variables. The study lacks generalization with a limited number of samples. Therefore, studies using more samples might be useful to validate the findings. However, this study concludes that there is a good prevalence of low-birth-weight babies and mothers have adequate knowledge regarding the low birth weight of babies and risk factors that affects the mother as well as the foetus. Mothers should have adequate knowledge regarding proper antenatal care, nutritional care and risk factors of low birth weight.

Data sharing statement provided by the authors is available with the full text of this article at jemds.com.

Financial or other competing interests: None.

Disclosure forms provided by the authors are available with the full text of this article at jemds.com. 


\section{REFERENCES}

[1] Aylward GP, Pfeiffer SI, Wright A, et al. Outcome studies of low-birth-weight infants published in the last decade: a meta-analysis. The Journal of Paediatrics 1989;115(4):515-20.

[2] Villar J, Belizán JM. The relative contribution of prematurity and foetal growth retardation to low birth weight in developing and developed societies. American Journal of Obstetrics and Gynecology 1982;143(7):7938.

[3] Parker JD, Schoendorf KC, Kiely JL, et al. Associations between measures of socioeconomic status and low birth weight, small for gestational age and premature delivery in the United States. Ann Epidemiol 1994;4(4):271-8.

[4] Offenbacher S, Katz V, Fertik G, et al. Periodontal infection as a possible risk factor for preterm low birth weight. Journal of Periodontology 1996;67(Suppl 10):1103-13.

[5] Anderson P, Doyle LW, Victorian Infant Collaborative Study Group. Neurobehavioral outcomes of school-age children born extremely low birth weight or very preterm in the 1990s. JAMA 2003;289(24):3264-72.

[6] Vaidya A. Size at birth: an examination of meaning and usefulness. a prospective study of a cohort of infants born in Nepal. Doctoral Thesis. UCL (University College London) 2009.

[7] Santos F. Use of anti-infective drugs during pregnancy: prevalence, predictors of use and the risk of preterm birth and small-for-gestational-age newborns. Thesis and Dissertation, University of Montreal. 2012.

[8] de Onis M, Habicht JP. Anthropometric reference data for international use: recommendations from a World Health Organization Expert Committee. The American Journal of Clinical Nutrition 1996;64(4):650-8.
[9] Shikuku DN, Milimo B, Ayebare E, et al. Practice and outcomes of neonatal resuscitation for newborns with birth asphyxia at Kakamega County General Hospital, Kenya: a direct observation study. BMC Pediatrics 2018;18:167.

[10] Aruna K. The prevalence of low birth weight and its risk factors among postnatal mothers in the selected hospital in Madurai. Masters Thesis, Matha College of Nursing, Manamadurai, 2010.

[11] Domple VK, Doibale MK, Nair A, et al. Assessment of maternal risk factors associated with low-birth-weight neonates at a tertiary hospital, Nanded, Maharashtra. Niger Med J 2016;57(1):37-43.

[12] Bansal P, Garg S, Upadhyay HP. Prevalence of low-birthweight babies and its association with socio-cultural and maternal risk factors among the institutional deliveries in Bharatpur, Nepal. Asian Journal of Medical Sciences 2019;10(1):77-85.

[13] Christian P, Khatry SK, Katz J, et al. Effects of alternative maternal micronutrient supplements on low birth weight in rural Nepal: double blind randomised community trial. BMJ 2003;326(7389):571.

[14] Lawn JE, Blencowe H, Oza S, et al. Every newborn: progress, priorities and potential beyond survival. Lancet 2014;384(9938):189-205.

[15] Roberts AK, Monzon-Bordonaba F, van Deerlin PG, et al. Association of polymorphism within the promoter of the tumor necrosis factor $\alpha$ gene with increased risk of preterm premature rupture of the fetal membranes. Am J Obstet Gynecol 1999;180(5):1297-302.

[16] Demissie K, Breckenridge MB, Rhoads GG. Infant and maternal outcomes in the pregnancies of asthmatic women. American Journal of Respiratory and Critical Care Medicine 1998;158(4):1091-5. 